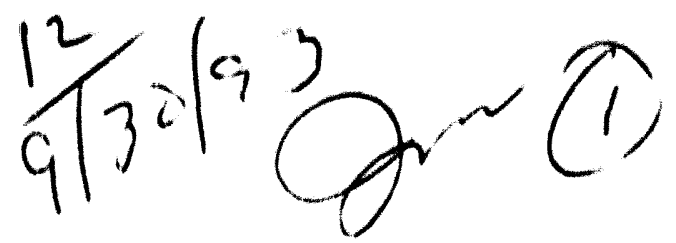

UCRL.ID. 114164

PREPRINT

PLUTONIUM DISPERSAL IN FIRES:

SUMMARY OF WHAT IS KNOWN

Ralph H. Condit

July 1993

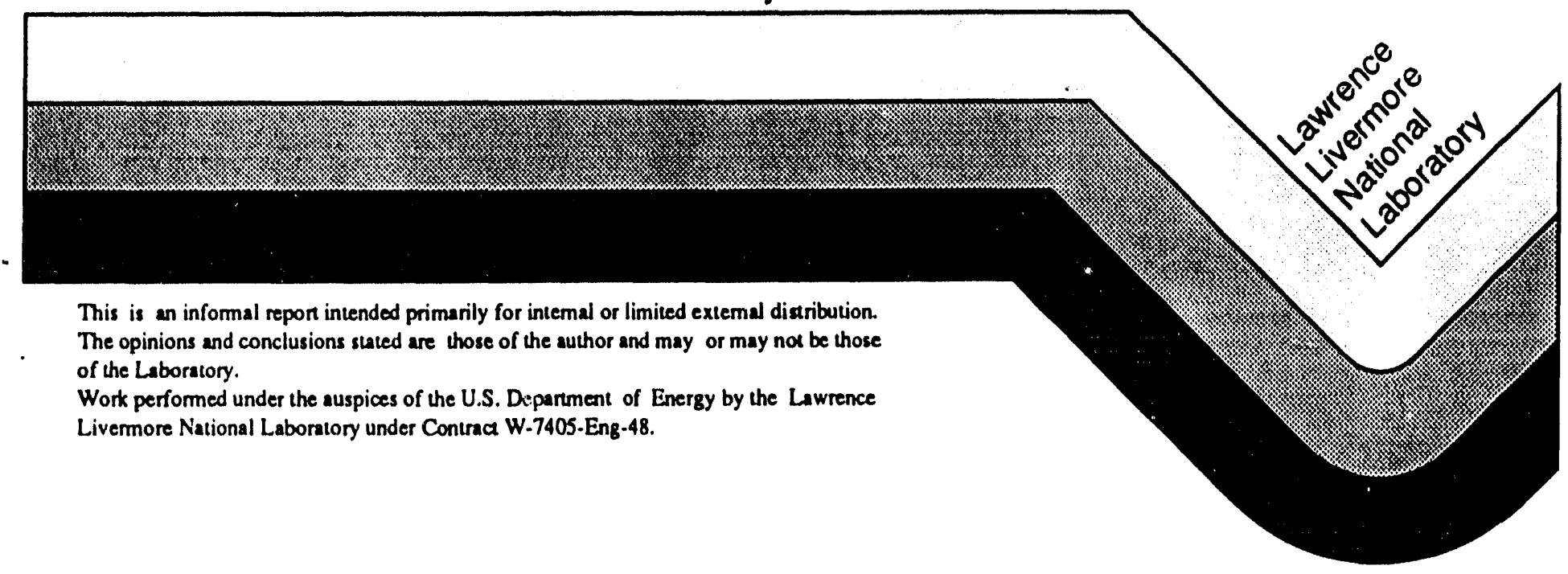

When - ep 


\section{DISCLAIMER}

This document was propared as an account of work sponsored by an agency of the United scatea Government. Nelther the United Statea Covernment nor the Univeralty of California nor any of their employeec, makea any warranty, expres or implied, or acoume any legal liability or respenstbility for the accuracy, completenese, or usufuinese of any information, apparatus, product, or proceas disclosed, or reprecents that lte use would not Infringe privately owned rights. Reference herein to any epecific commerdal products procsest or earvice by trade name, trademark, manufacture, or otherwise, dow nol neceasarlly conatltute or imply its endornement, recommendation, of favoring by the Uniled Scater Government or the Univerally of Callfornila. The viewe and opintons of authors expreseed hereln do not necesearlly state or reflect those of the United States Government or the Univeraty of Callfornia, and shall not be used for advertising or product endorsement purposes.

Thls report has been reproduced directly from the beat avallable copy.

Avallable to DOE and DOE contractors from the Omee of Scientific and Technical Information

P.O. Box 62, Oak Ridee, TN 37831

Prices available from (615) 576.8401, FTS 626.8401

Avallable to the public from the

National Technical Information Service

US. Department of Commerce

5285 Port Royal Rd.,

Springfield, VA 22161 


\title{
Plutonium Dispersal in Fires: Summary of What is Known
}

\author{
14 \\ Ralph H. Condit
}

October, 1986

Plutonium Technology

Chemistry and Materials Science Department Lawrence Livermore National Laboratory 
In this pamphlet pages are arranged in pairs. The righthand sheet is reproduced from a viewgraph, the lefthand contains supporting text.

\section{INTRODUCTION and CONCLUSIONS}

In view of the great public apprehension about plutonium and nuclear weapons we should explore ways to prevent, limit, or mitigate possible plutonium dispersals. This review is primarily a tutorial on what 18 known about plutonium dispersal in fires.

It concludes that in most types of fires involving plutonium the amount released will not be an immediate danger to life. Indeed, in many cases very few personnel will recelve more than the lung burden allowed by current regulations for plutonlum workers. However, the dangers may be significant in special situations, unusual terrains, certain meteorological conditions, and very high burn temperatures.

\section{CONTENTS:}

Introduction and Conclusions . page 1

The Problem

Plutoniumu dispersal - the respirable fraction 3

Plutonium toxicity 5

Available Data

History of plutonium dispersal events 7

Plutonium Dispersal Studies Program 9

Burn studies 9

Solid residues and airborne fractions 11

Respirable aerosol fractions produced in burning 13

Effects of meteorological conditions on dispersal 13

Vixen A experiment - respirable fractions 15

Vixen A experiment - ground deposition 17

Resuspension 17

$\begin{array}{ll}\text { Cleanup costs } & 17\end{array}$

Summary of R\&D knowns/unknowns

What affects aerosol fractions in plutonium burning 19

Supplementary Information

Plutonium technical fact sheet 21

Glossary

back cover

Acknowledgements: This compilation of material has been helped greatly by the Sandia National Laboratory's Plutonium Dispersal Studies Program and the Lawrence Livermore National Laboratory's Hazards Control and Envirodnmental Sciences Divisions 
The happiest words we might hear in the event of a weapons accident could be "There was no plutonium release."

In an accident involving nuclear weapons and/or plutonium any dispersal would have enormous political consequences.

At the same time, the actual dangers to a population exposed to a plutonium burn accident would be of the same magnitude as those now accepted in the chemical and transportation industries. 
page 3

PLUTONIUM DISPERSAL - THE RESPIRABLE FRACTION

Plutonium dieperal studies are mainly concerned with assessing what fraction of the plutonium becomes airborne, 18 respirable, and is likely to be retained in the lung. Knowing this fraction is important, because plutonium 18 most dangerous when Inhaled. Plutonium ingested into the stomach 18 less toxic by a factor of at least 100 for even its soluble compounds. Plutonium injected directly into the blood 18 more dangerous but the contribution from this type of injury to the overall impact of a plutonium accident is normally sma11. The area around an accident scene may be littered with chunks of plutonium or piles of oxide, but this material can normally be collected more easily than the fallout from a dispersed aerosol. External irradiation injury from alpha paricles can be easily shielded.

The accompanying figures indicate the course of plutonium through the body. Material inhaled may lodge in the upper respiratory tract, URT, or in the lower respiratory tract, LRT, the pulmonary region, lungs. While there is no sharp boundary in dependence on particle size, the respirable size (those particles which will lodge in the lung) may be defined as less than 5 um.

Material in the URT will mostly transfer to the gastrointestinal tract (81\%) while some will move to the lungs (18\%). The biological half-life in the lungs is about 500 days which means that about half this material will have gone elsewhere after that time. The residence time depends on the chemical state of plutonium in the particles.

Once plutonium has settled onto the ground it may be resuspended by wind or other agitation or may become mixed into the soil where it is relatively harmless. While the immediate health hazards from the initial fallout cloud are greater than from the resuspended material, the cleanup requirements are somewhat governed by the resuspension characteristics of the area affected.

A plutonium dispersal accident is an Intrinsically uncontrolled event. Many of the Individual phenomena in the process have been characterized but the way in which they combine is unpredictable. Therefore, any prediction about amounts of dispersal is going to appear in the form of a probability statement. In addition, since human illnesses, especially latent cancer deaths initiated by radio- activity, are expressed as a probablility based on a dose, there can be no simple safe/unsafe boundary to the effects. This presents problems for lawyers, but that is the way the real world works. 
page 4

\section{Plutonium migration in the body}

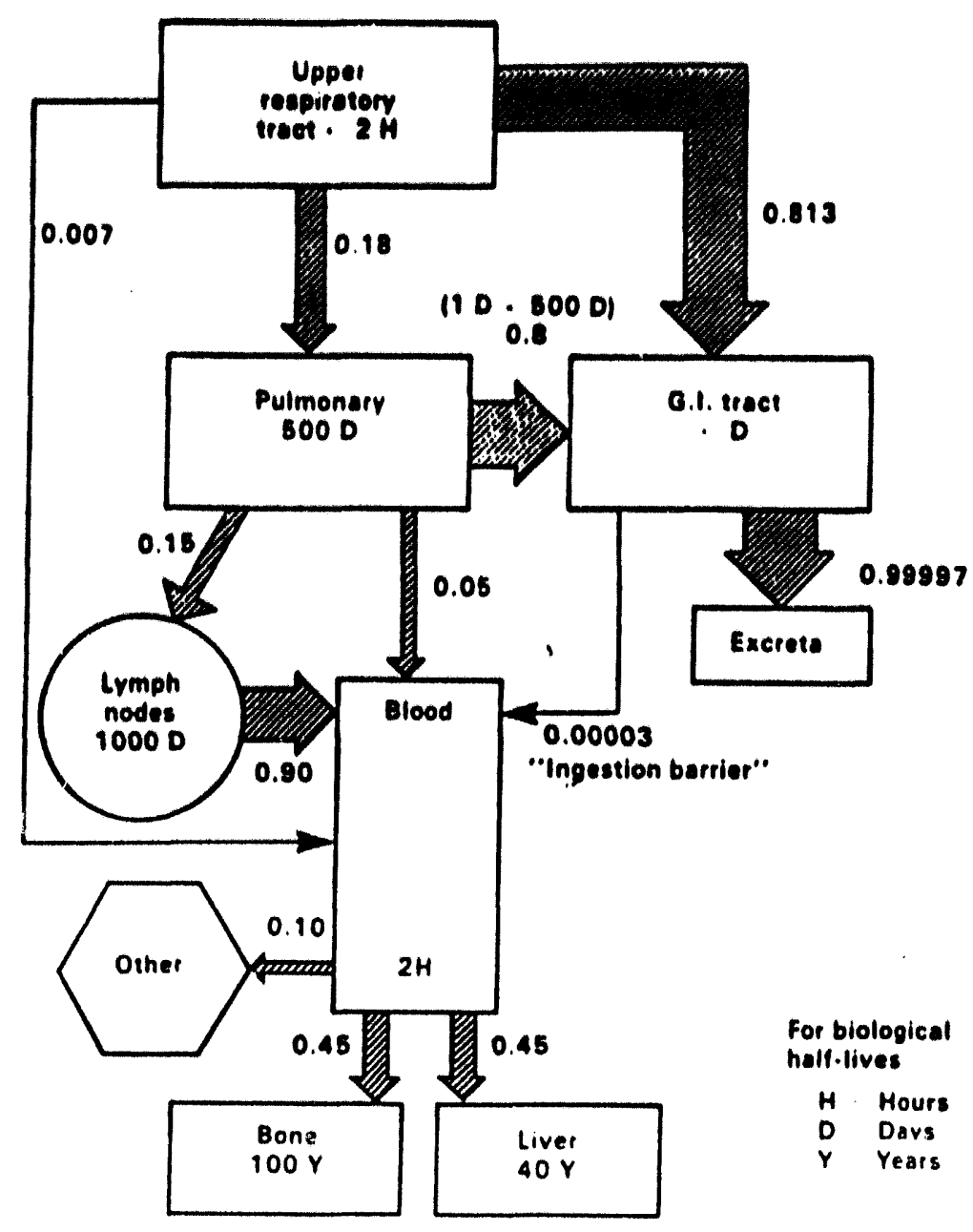

\section{Plutonium captured in the respiratory system}

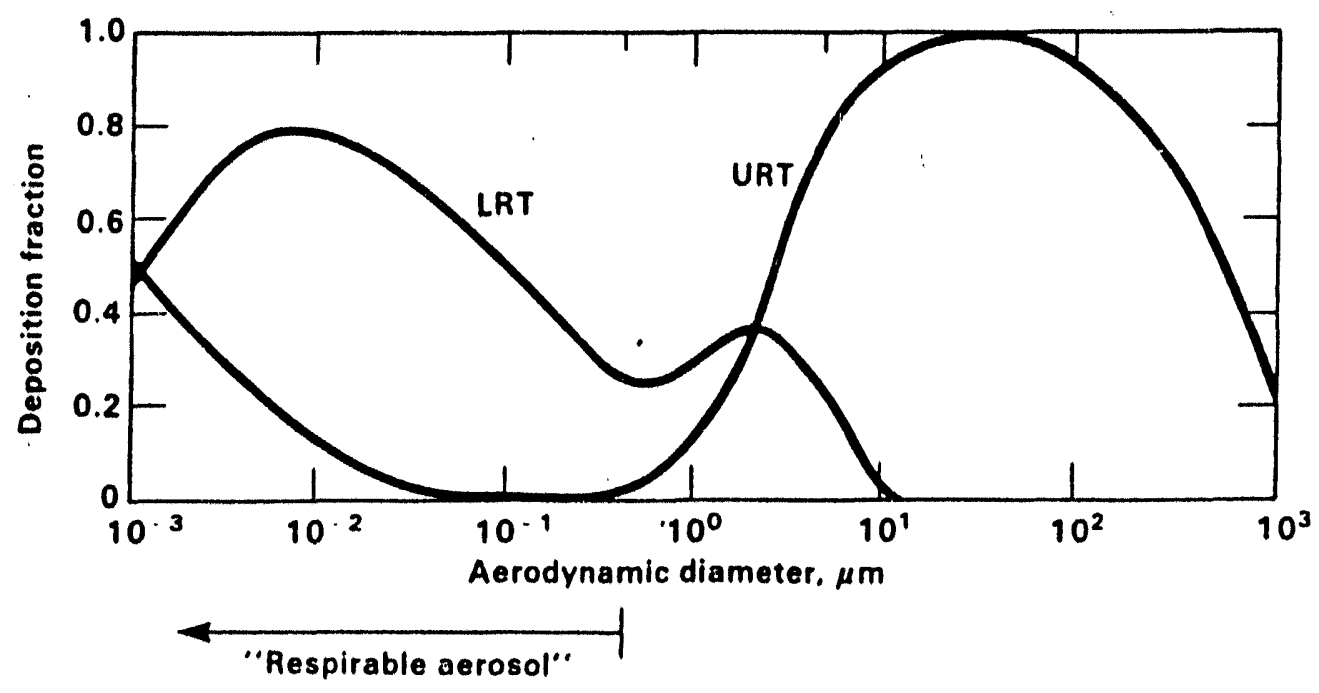


page 5

PLUTONIUM TOXICITY

While plutonium is NOT the "most toxic substance known to man", It is a dengerous material. Understanding the nature of 1ts toxicity requires that we distinguish between (1) acute effects, (2) nonstochastic effects, and (3) etochastic affects.

Acute effects caused by radiation doses greater than 100 rem include nausea, lowered blood count, 1088 of ha1r, and death.

Non-stochastic effects include the acute effects but also include delayed effects such as nonmalignant skin damage, induction of cataracts, and 1088 of fertility. Non-stochastic effects are measurable in individuals responding to their personal exposures to radiation.

Stochastic effects have a statistical character, the increased probablility of occurrence of cancer in a large population each member of which has been exposed to radiation.

Prompt fatilities resulting from inhalation of plutonium:

The amount of plutonium which might be expected to cause death within 30 days is $4.3 \mathrm{mg}$ uniformly "distributed in the lungs.

Latent cancer deaths (LCD) caused by radioactivity:

The number of latent cancer deaths induced by relatively low radiation exposures in a population is often taken to be 1 death per year per 50,000 person-rem exposure. That is, a 1-rem dose to 50,000 or 10 rem to 5,000 people will induce 1 death per year by cancer during the life times remaining in that population.

Genetic effects:

Genetic disorders resulting from 1 rem per generation are estimated as 5-65 per million population in the first generation.

The EPA allowed plutonium contamination levels:

The maximum allowed burden of plutonium in lungs for plutonium workers is $0.016 \mathrm{uCi}$. This is believed to increase the probability of lung cancer by about $1 \times 10 \mathrm{E}-4$ in that person.

The allowed plutonium concentration in soil is $14 \mathrm{pCi} / \mathrm{g}$. One $\mathrm{pCi}$ is 2.22 atomic disintegrations per minute. This activity level is roughly the same as the average of what is already present.

The allowed plutonium concentration in air is $0.06 \mathrm{pCi} / \mathrm{m} 3$. 
page 6

\section{Plutonium toxicity}

Prompt fatality ( 30 days)

In lungs $4.3 \mathrm{mg}=2.6 \times 10 \mathrm{E}-4$ Curie

Allowed burden:

In lungs $0.3 \mathrm{ug}=1.6 \times 10 \mathrm{E}-8$ Curie

(Liable to increase probability of cancer death by about $1 / 10,000$ ) 
page 7

HISTORY OF PLUTONIUN DISPERSAL EVENTS

There have been about dozen alrcraft and missile accidents in which some plutonium was released. Three are mentioned here.

McGuire AFB, N.J., 1960. A Bomarc missile burned on 1ts pad spreading a small amount of radioactivity around the s1lo. A 1985 article in the New York Times reported that the governor of New Jersey had only recently learned about the accident, was very upset, and wanted to open a new investigation.

Palomares, Spain, 1966. In a midair collision one B28 weapon dropped Into the sea and two one-point detonated and dispersed $\mathrm{Pu}$ on impact with the land. 80 million dollars was spent in decontaminating the land, in retrieval of the weapon lost at sea, and medical exams of residents. An additional 20 million was spent in reparations and other costs. About 4,600 separate 55 gallon drums of contaminated soll were shipped to Savannah River.

Thule, Greenland, 1968. A bomber crash and fire resulted in one-point detonation of four weapons . About 237,000 cubic feet of contaminated ice, snow, and crash debris were removed to SRP.

Also, in 1969 a fire at the Rocky Flats Plant released about 880 uC1 of plutoniumn. While this was a costly event the release was much less than earlier releases $(3.4 \mathrm{C} 1$ ) resulting from leaking waste containers and the soil disturbance associated with their cleanup.

Experiments:

The Vixen A, Australia, 1959. Pu metal was burned in a fuel fire and the dispersal measured. This is described in following sheets.

Plumbbob (1957) and Roller Coaster (1962-63) were tests at NTS in which weapons were one-point detonated and the fallout measured.

Laboratory burn experiments have been conducted by Mishima (196066) at BNVL to test various burn scenarios: Pu solutions mixed with fuel, Pu scattered on flat surfaces, and mixed with paper materials. Stewart (1959-63) at AWRE has conducted corrosion and burn studies and wrote up the Vixen A experiment. The PAGE program is mentioned on the following page. Recently ITRI (Inhalation Toxicology Research Institute), Albuquerque, has been measuring aerosol generation on burning $\mathrm{Pu}$ and its alloys with $\mathrm{Fe}$ and $\mathrm{U}$ in a variety of gases including those released by decomposing IHE, see pages 7 and 13 .

The Plutonium Dispersal Study Program, PDSP, at SNLA is an extensive calculational and experimental program. It is discussed in detail on the following page. 
History of Pu dispersal events

Accidents:

McGuire AFB

Palomares

Thule RFP
1960, New Jersey

1966, Spain

1968, Greenland

1969, RFP

Field experiments - burning:

Vixen $A$

Field experiments

Plumbbob

Roller. Coaster
1959, Australia

one-point detonations:

1957, NTS

1962:63, NTS

Laboratory burn studies:

Mishima

Stewart

PAGE

'ITRI

Other:

PDSP
1960-66, BNWL

1959-63, AWRE

1974. Albuquerque

1981-85, Albuquerque

1981-87, SNLA 
page 9

THE PLUTONIUM DISPERSAL STUIIES PROGRAM (PDSP)

Robert E. Luna heads the Plutonium [Lsepersal Studies Program (PDSP) at Sandia National Laborator1es, Albuquerque. It 1o primar1ly concerned with plutonium dispersal in weapon explosions. He recelves about 30 problems a year which he handles using the codes referenced below. His present program is running at about 1.5 FTE. He plans to publish this code set developed over the past decade during FY87.

As now developed, the PSDP analyals takes the dieperas process through (1) the implosion which compresses and heate the plutonium, (2) the decompression relesse which yields plutonium as anixture of solid fragmente, 1iquid, and vapor, (3) the trajectories of these componente with attention to ablation of solld chunke flying through the air, IIquid droplet breakup, and vapor reaction with alr to form oxide, (4) the entrainment of the resultant particulates in the plume from the explosive or, In the case of ablated materlal from chunku thrown beyond the plume, the entrainment of the particulates in the air motion accompanying the plume, and (5) the migration of the plume cloud, and (6) finaliy the fallout from the cloud to 8 ive a pattern of deposition on the ground.

The PDSP computer analysis of plutonium dispersal has been tied with experimental data using urantum as atand-in for plutonium. There is good agreement between prediction and experiment and the research group believes that knowing the equations of state of $P u$ and $U$ allows a transposing to results from $U$ to Pu dispersal. The input for their calculations includes actual weapon parameters.

\section{BURN STUDIES}

With the introduction of IHE the danger of a weapon explosions has decreased. The worry about accident scenarlos has shifted somewhat to fire (quiescent or propellant) and the ITRI study of burning in IHE decomposition gases has been mentioned on page 7 . We continue to be interested in the higher temperature burns which might ocur in propellant fires. High temperature burn studies have been carried out using proxy materials for plutonium, mainly uranium, in the PAGE (Plutonium Aerosol Generation Experiment8) Program at SNLA in the early 1970 's. In this program liquid droplets were ignited and allowed to drop through air. A current program at SNLA is also concerned with metal droplet burning. This does not now employ Pu but will use U. The purpose will be to study burn of droplets traveling at near sonic velocities through air. This means that the reaction is not 1 imited by diffusion processes in the gas phase. Initial tests of the equipment are using $N i$ and $W$. 


\title{
pagge 10
}

\section{Pu Dispersal Studies Program}

\author{
Ixplosion colculations \\ Implosion \\ Violde of solld, llquild, vapor \\ sise diatributions and irajectories \\ Voloelty of llquid dropiete and breakup \\ Entrainment of aerosol in plume \\ Alse and drift of the cloud \\ Falloue from the cloud
}

Burn studies

ITRI

High velocity droplets 
page 11

\section{SOLID RESIDUES AND AIRBORNE FRACTIONS}

Plutonium metal reacts in air to form the oxide Pu02. Further details about plutonium corrosion and burning are given in a fact sheet at the end of this report. Plutonium axides are high melting point, non-volatile materials and most of the oxide remains around the metal as it burns. The oxide particles may range from millimeters down to fractions of a micron. A small fraction, some of those particles less than a few tens of microns, do become airborne. Some of the airborne material is within the respirable range (less than $5 \mathrm{um}$ ).

A study at the Inhalation Toxicology Reseach Institute (ITRI) was initiated in 1981. This effort was jointly sponsored by LANL, LLNL and SNLA. The first intention was to see if the IHE decomposition and combustion products would have a significant effect on the aerosol

- fraction for Pu. It was found that those gases had little effect, but the study was extended to $\mathrm{Pu}-\mathrm{U}$ and $\mathrm{Pu}-\mathrm{Fe}$ alloys which did under certain cirumstances generate a relatively large fracton of aerosol (toward 1\%). It may be that this relatively large value is partly an experimental artifact; the reaction product re-ignited as the equipment was being disassembled after the experiment and additional material carried over to the aerosol collectors. This result is important in itself, because it underlines the need for care in cleanup procedures following a fire.

In the accompanying probability chart two particle size distributions are shown for powders formed in a reaction between plutonium metal exposed first to hydrogen and.then to air. The aerodynamic diameters are plotted assuming a particle density of 1 $\mathrm{g} / \mathrm{cm} 3$. This distribution is not typical; data points usually fall along one fairly straight line on a probability chart. The particle size distribution here is bimodal. Larger particles were probably formed during cracking and flaking at the time of hydriding. The smaller particles may then have formed during reaction of the hydride with air

Particles sizes are generally measured as an aerodynamic diameter where it is assumed that the particles have a density of $1 \mathrm{~g} / \mathrm{cm} 3$. The crystal density of $\mathrm{Pu} 02$ is $11.46 \mathrm{~g} / \mathrm{cm} 3$, but the actual plutonium particles are rarely hard spheres; rather they may be clumps or strings of finer particles with effective densities much less.

The settling rates of particles, $\mathrm{cm} / \mathrm{sec}$, calculated by Stokes law are:

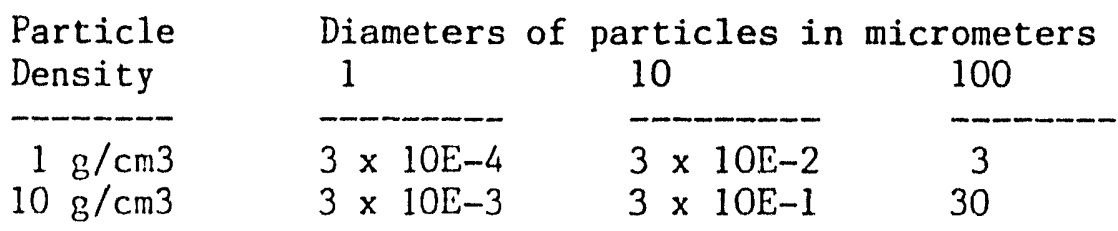


page 12

\section{Plutonium particle size distribution}
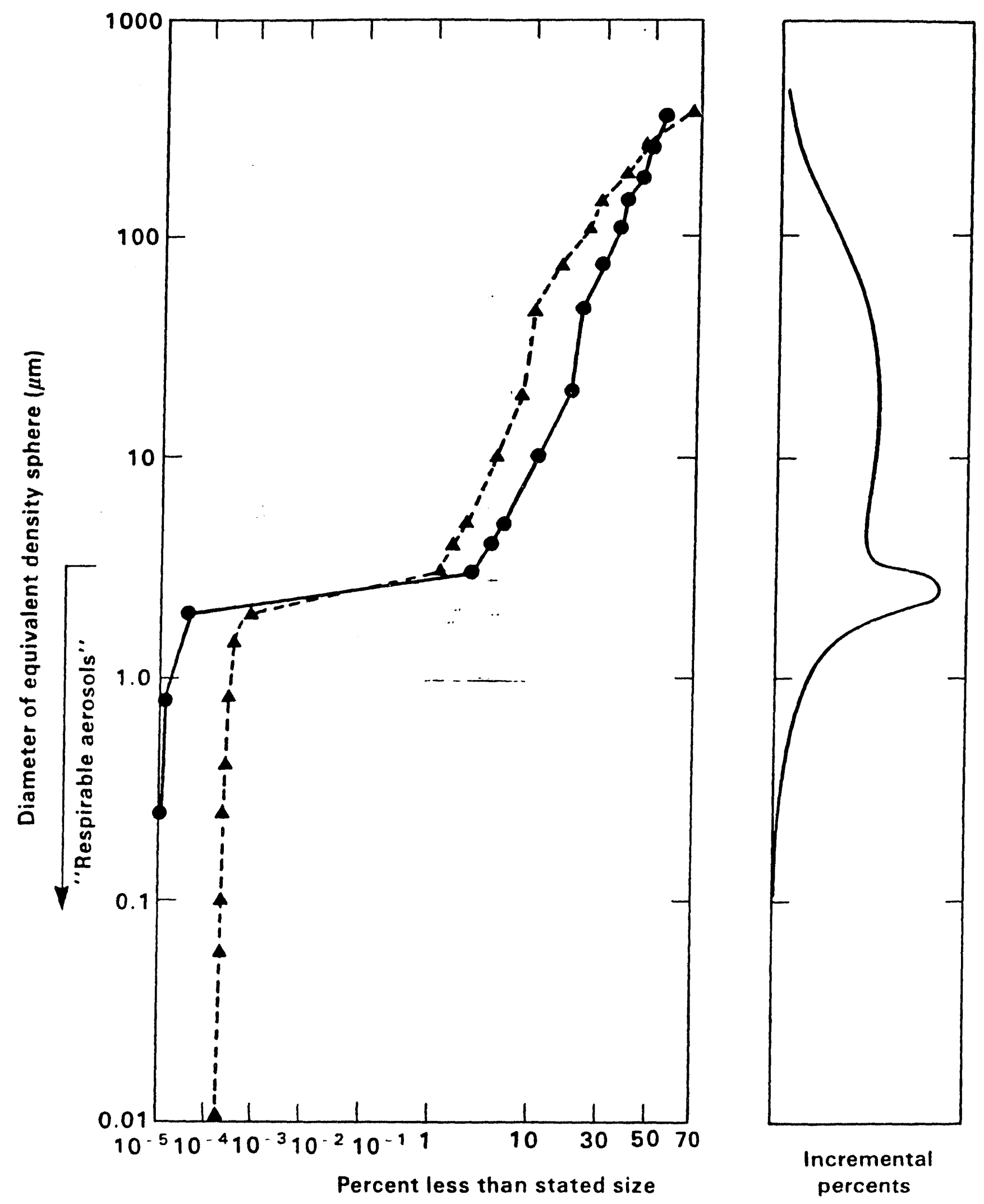
page 13

\section{RESPIRABLE AEROSOL FRACTIONS PRODUCED IN BURNING}

The accompanying figure shows the fraction of plutonium converted to a respirable aerosol (the fraction of oxide having a particle size smaller than $5 \mathrm{um}$ ) measured in all experiments ever reported. The results of this data survey are shown in two ways, as a bell shaped curve on the right and as an integral probability plot on the left. It can be seen that the median aerosol fraction is around $6 \times 10 E-4$ with steps of standard deviation from this being roughly a decade on the logarithmic ordinates. Thus, if we know nothing about the source term for burning plutonium this provides us with statistical guidance. Factors which influence the burning mechanisms and lead to large or small aerosol fractions are discussed further on page 19.

In a few cases the fraction of plutonium aerosolized as it burns in air is below 10E-5; in some cases it is as high as a few percent. It should be noted that the Vixen $A$ result was in the $1 \%$ range. This is probably a result of allowing the oxide to drop through the flame as the plutonium burned. There seems to be some dependence on the temperature of the plutonium as it burns, on the alloying of the plutonium, and in some cases on previous reactions of plutonium with other gases such as hydrogen. There appears to be little dependence of the reaction on the air flow rate, the composition of the reaction gases including those to be expected from the decomposition of IHE, or on the surface to volume ratio of the specimens used.

\section{EFFECTS OF METEOROLGICAL CONDITIONS ON DISPERSAL}

\section{events:}

Meteorological conditions will differ greatly between dispersal

wind velocity, direction constancy, atmospheric temperature gradients which may include an inversion layer tending to limit the rise of the fire plume, wind shear which may carry part of the aerosol to great distances while depositing another locally, and fog or rain which may promote fallout.

Surface features such as hills, depressions, buildings, and trees will also have an influence on fallout patterns. As a result, the concentration of plutonium on the ground at one spot may be acceptable while immediately surrounding spots may not. Thus, the exact pattern of fallout will always be hard to predict even with a good source term. However, the factors contributing to dispersal have been characterized and the statistical features governing the overall process have been modeled. 

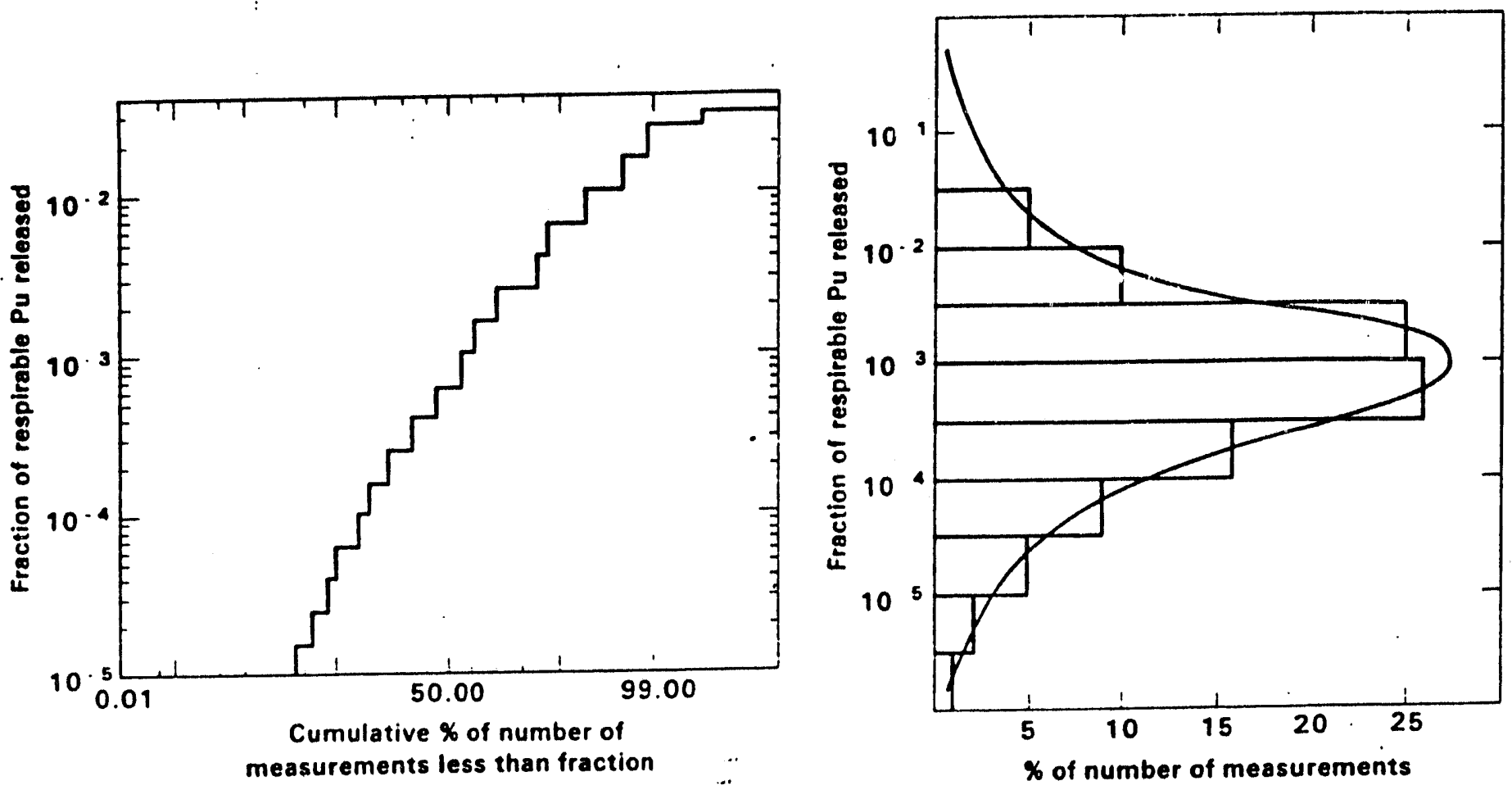
page 15

THE VIXEN A EXPERIMENT - RESPIRABLE FRACTIONS

The Vixen A program in Australia in 1959 included two plutonium burn experiments. In each a 200 gram piece was suspended in a steel basket above a gasoline fire at $1100 \mathrm{C}$. The accompanying figure gives a composite of the data normalized to $1 \mathrm{~kg}$ of $\mathrm{Pu}$ per experiment. Each dot represents one measurement of the amount of plutonium collected from air drawn through a filter. These filters were designed to collect about the same amount of plutonium aerosol as a human would inhale if he were to stand at the given location throughout the experiment. The filtiers were positioned at various distances downwind from the fire. The wind velocity was about $10 \mathrm{mph}$ and varied in direction within about 45 degrees during the burn.

The abcissa is a logarithmic scale of distance from the source. The ordinate is the weight of $\mathrm{Pu}$ collected on each filter. On the right side this weight is translated into curles of $\mathrm{Pu}$. The permitted lung burden is $1.6 \times 10 \mathrm{E}-8 \mathrm{C}$. A lung burden causing death within 30 days would probably be about $3 \times 10 \mathrm{E}-4 \mathrm{Ci}$. The effect of less than fatal amounts would be to increase the probability of latent cancer deaths (LCD) above the normal rate. The scale on the far right shows these probabilities. For example, an LCD probability of $10 \mathrm{E}-2$ means that in an exposed population there would be a $1 \%$ increased death rate due to radiation induced cancers compared with the death rate in the absence of the exposure.

For a population density of 10,000 per square mile, typical of city areas, the number of people within a radius of the source and down-wind within a 45 sector can be calculated as shown along the top scale.

Possible Magnifiers:

A pair of dashed lines bounds the data on the lower and upper side. The upper range of data suggests a reasonable indicator of what our concern should be. This upper range might have been higher under a variety of circumstances:

1. If $10 \mathrm{~kg}$ of $\mathrm{Pu}$ had been burned rather than the $1 \mathrm{~kg}$ for which the data haw been plotted, a factor of $10 \mathrm{X}$.

2. If the fraction of plutonium converted to respirable aerosol had been $100 \%$ rather than the few \% actually observed, say $100 \mathrm{X}$.

3. If meterological conditions had been different, no wind, the amount deposited close to the fire could have been greater by perhaps a factor of 100. This factor has not been added here, but would appear as a tilting of the range lines. Meteorological considerations are mentioned on the previous page. 

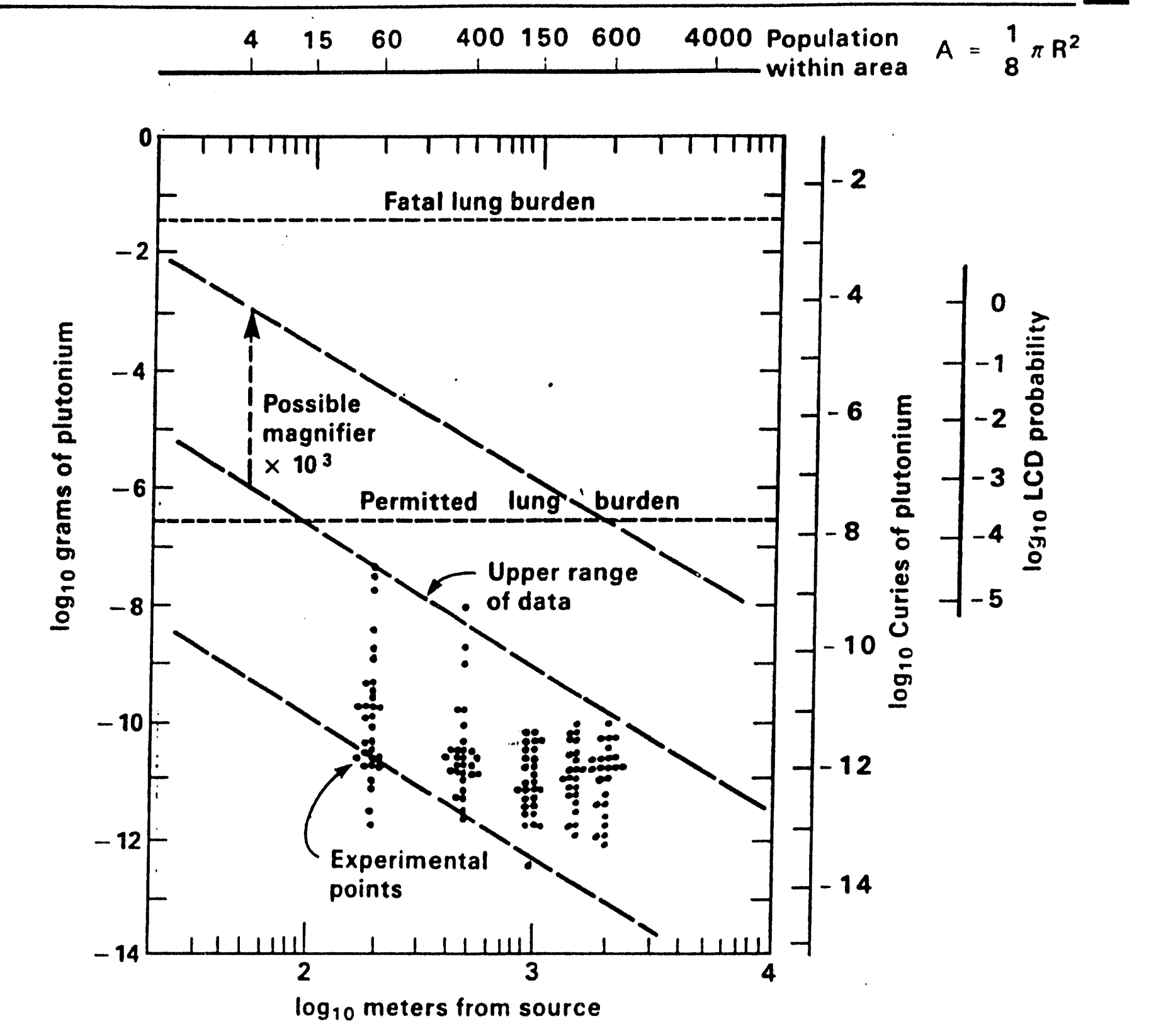

VIXEN-A Experiment

Respirable amounts of plutonium

- Data normalized to $1 \mathrm{KG}$ source

- Possible magnifiers: (not including meteorological factors)

Mass Pu $1 \rightarrow 10 \mathrm{~kg}$ Aerosol fract. $1-100 \%$

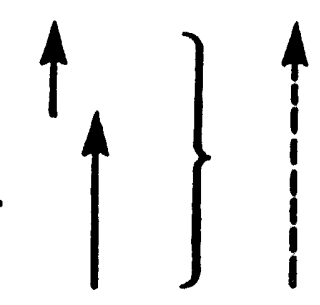


page 17

THE VIXEN A EXPERIMIENT - GROUND DEPOSITION

The accompanying figure shows the deposition of plutonium on the ground following burning in the Vixen A experiments. The concentration in curies per sq. meter is given as a function of distance downwind from the source. Many of the terms in this figure are the same as in the previous one.

The EPA allows a concentration of plutonium in the soil of 14 picocuries per gram. The EPA "allowed" density calculated here assumes that the deposit has been mixed to a depth of 6 inches $(15 \mathrm{~cm})$.

\section{RESUSPENSION}

After the plutonium aerosol has settled, it may be resuspended again, become a respirable aerosol, and be further dispersed. Such resuspension may occur as a result of winds and disturbance of the surface such as by plowing. The aerosol resulting from resuspension is very much less than in the initial fallout cloud but can raise the air concentration above the EPA allowance for people residing in the area.

Resuspension factors have been reported which span nine orders of magnitude. They depend on the state of initially deposited plutonium particles (chemical composition, degree of agglomeration of smaller particles) and the type of surface (smooth, asphalt, sand). Large resuspension factors imply easy migration of the contamination and short times for its retention at the given location; contamination moves to areas where the factor is small, i.e. it is trapped for long times.

\section{CLEANUP COSTS}

Cleanup costs have been estimated as $\$ 0.10$ per square meter for the case when the surface deposit is merely plowed under or is scraped into a nearby ditch. If the surface layer needs to be collected and shipped to a distant disposal site, costs would more likely be $\$ 10$ per square meter. The is picked as the basis for the top scale. Cleanup in urban areas might well be greater.

The accompanying figure may be used to estimate implications of various resuspension factors on cleanup costs. The air concentration of plutonium is a principal factor driving the need for cleanup and hence the cost. In using this graph one might, for example, look at the right scale, assume a resuspension factor of $10 \mathrm{E}-9$ (probably a reasonable value for open land), read over to the left until meeting the magnifier line (to be conservative), and read up to the cost scale at the top to find a cleanup cost of between $\$ 1,000,000$ and $\$ 10,000,000$. In the Palomares accident the costs came to about $\$ 100,000,000$ for weapon retrieval, cleanup, and reparations. 


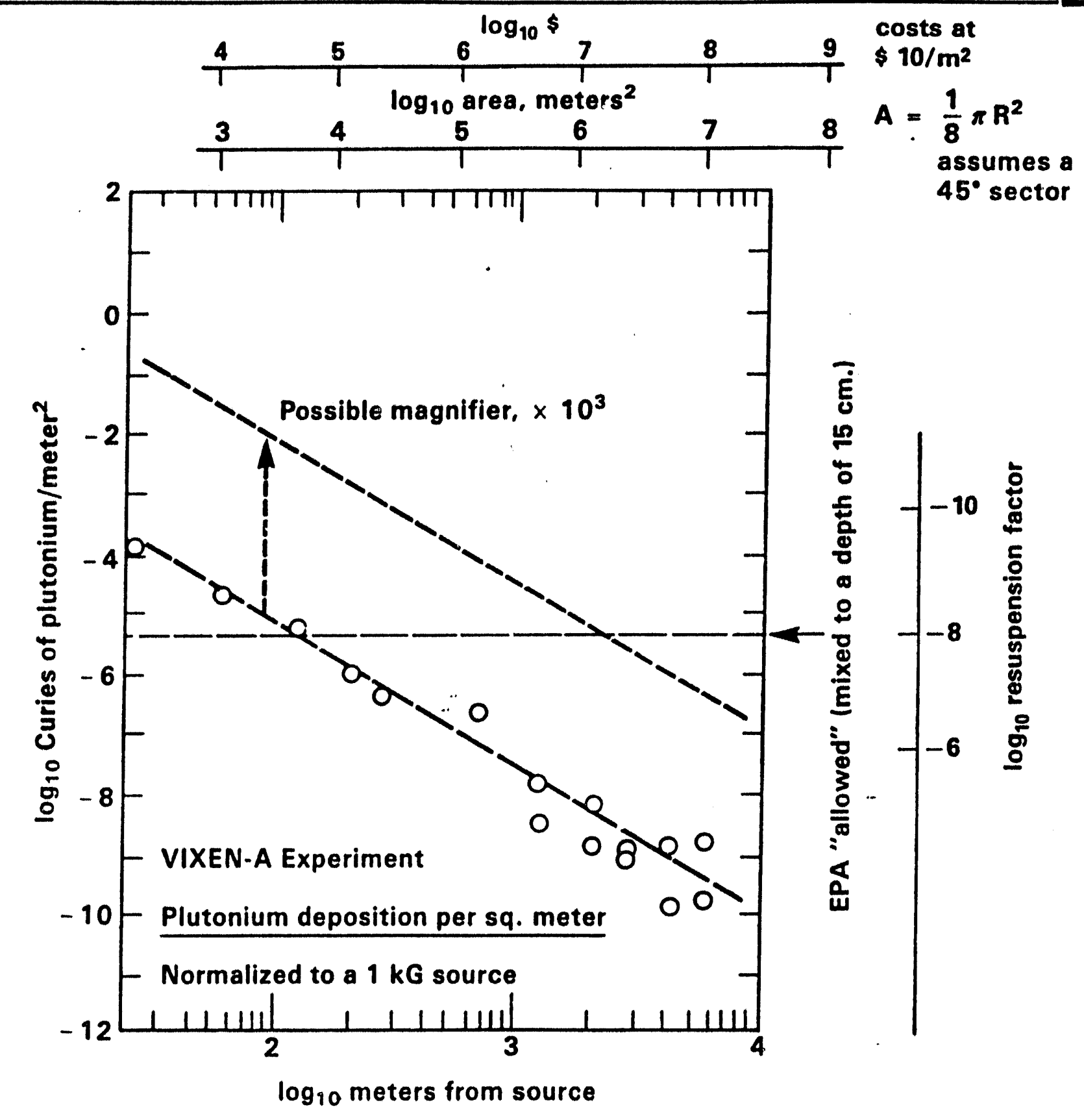


page 19

WHAT AFFECTS THE AEROSOLIZATION FRACTION IN PLUTONIUN BURNING?

Minor effects:

Factors which seem to have little effect on the aerosolization fraction include the mass of the sample, the area to volume ratio, the gas composition, and the gas flow rates up to the point where the gas entrains fragments of burning metal.

\section{Significant Effects:}

Tumbling of products through a gas stream may yield high aerosol fractions. In the Vixen experiment the oxide product sifted through the flame to a collection tray placed under a basket holding the $\mathrm{Pu}$.

Temperatures up to perhaps $1500 \mathrm{C}$ result in a decreasing aerosol fraction. Presumably the oxide sinters and larger particles result. At higher temperatures, plutonium vaporization may contribute significantly to a vapor-air reaction yielding small particles.

Alloying of the Pu can be important. Alpha and delta-plutonium yield similar aerosol fractions. If plutonium is alloyed with uranium or iron the fraction is slightly larger.

The chemical state of the Pu, particularly the sequence of chemical reactions has an effect. Plutonium rẹacted first with hydrogen and then with air yields a larger fraction of aerosol, particularly for some $\mathrm{Pu}$ alloys than does hydriding or air alone.

What is not known about Pu Dispersal:

Much remains unknown about the burning of $\mathrm{Pu}$ alloys below $1100 \mathrm{C}$. On the basis of experience with other metals, it seems possible that small alloy additions to $\mathrm{Pu}$ could change its burning rate and the aerosolization factor by one or two orders of magnitude.

Little is known about the high temperature burning of $\mathrm{Pu}$. All studies have used proxy materials. It seems possible that volatiles like Am, $\mathrm{Ga}$, and He (in aged $\mathrm{Pu}$ ) could play a role in dispersal.

Ways to prevent, supress, or mitigate possible $\mathrm{Pu}$ dispersal:

Fire resistant pits offer one way to prevent $\mathrm{Pu}$ dispersal.

Fire fighting and cleanup techniques might be reexamined. The burning of $\mathrm{Pu}$ metal may be incomplete, and remaining pyrophoric material may reignite even after a fire has been extinguished.

Cloud seeding to promote $\mathrm{Pu}$ oxide particle agglomeration may be feasible in some instances. 
What affects the aerosolization fraction in plutonium burning?

Little effect:

Mass of the sample

Area to volume ratio

Gas flow rates

Gas chemistry by itself (complex

alloy interactions)

Significant effect:

Tumbling of reaction products through the gas stream

Temperature

Fraction decreases up to around $1500 \mathrm{C}$ (oxide sintering)

Fraction increases at higher temperatures (Pu vaporization)

Alloying of the $\mathrm{Pu}$

Chemical state of the $\mathrm{Pu}$

Unknowns:

Processes at high temperature

Broader experience with alloying

Age of $\mathrm{Pu}$

Helium

Americium

Optimum firefightirig and cleanup techniques 
page 21

PLUTONIUM TECHNICAL FACT SHEET

\section{Radioactivity:}

The half-lives and decay modes are 1isted in an accompanying table for the mixture of radioactive species characteristic of weapons grade plutonium. The specific radioactivity which is commonly mentioned, 0.08 $\mathrm{C} 1 / 8$, refers to alpha decay, because that is of greatest. biological importance. The range of $5.1 \mathrm{MeV}$ alpha particles is $3.7 \mathrm{~cm}$ in air, 43 $\mu \mathrm{m}$ in biological tissue, and $9 \mu \mathrm{m}$ in plutonium metal.

The metallic element:

The pure metal transforms through six crystal phases on heating to Its melting point at $640^{\circ} \mathrm{C}$. The normal room temperature phase is alpha$\mathrm{Pu}$, stable to about $120 \mathrm{C}$ (sp. gravity 19.86). Beta-Pu is stable from $120^{\circ}$ to $207^{\circ} \mathrm{C}$ (8p. gravity 17.7 ). The delta phase, normally stable from $315^{\circ}$ to $457^{\circ} \mathrm{C}$, has a face-centered-cubic crystal structure and can be made room-temperature stable by the addition of 3 atom 7 gallium (ap. gravity 15.9 when stabilized at room temperature).

The mechanical properties of $\mathrm{Pu}$ vary dramatically among the metal phases and alloys. Alpha $\mathrm{Pu}$ is a strong-brittle material resembling cast iron. Delta stabilized $\mathrm{Pu}$, on the other hand, deforms much like high purity, soft copper. The mechanical properties of $\mathrm{Pu}$ alloys are sensitive to small changes in composition and to the conditions under which they are deformed.

The physical properties of $\mathrm{Pu}$ also show unusual behavior, Thermal expansion is near zero for delta-stabilized Pu but about $55 \times 10 E-6$ for alpha $\mathrm{Pu}$, higher than for most metals. Pu also expands on freezing (like water). It conducts heat and electricity poorly for a metal; in delta-stabilized $\mathrm{Pu}$ the thermal conductivity is 0.9 watts $/ \mathrm{cm} /{ }^{\circ} \mathrm{C}$ at $100^{\circ} \mathrm{C}$ and the thermal diffusivity is $0.0043 \mathrm{~cm} 2 / \mathrm{sec}$. Molten Pu has unusually high viscosity for a molten metal, 6 centipoises at $650^{\circ} \mathrm{C}$. Its liquid surface tension is around 500 dyne $/ \mathrm{cm}$ at $640^{\circ} \mathrm{C}$.

\section{Chemical reactions:}

The metal reacts in air to first form the oxide, Pu203, and eventually Pu02. A large piece reacts slowly, initially, a tarnishing discoloration, but in time it converts to the gray-green, sometimes yellow dioxide powder. In humid air alpha-Pu can corrode at nearly 10 $\mu \mathrm{m} /$ hour. The rate for delta-Pu is $1 / 10$ of this. Corrosion rates in dry air are less by a factor of 1000 . Massive Pu does not burn unless heated to about $500^{\circ} \mathrm{C}$. Very fine filings can ignite spontaneously. Plutonium burns quietly like charcoal briquettes in a barbeque.

The metal reacts with water to form an insoluble gelatinous sludge. At room temperature alpha-Pu reacts with seawater at a rate of 0.8 $\mathrm{mm} / \mathrm{hour}$ while stabilized delta-Pu dissolves at $0.005 \mathrm{~mm} / \mathrm{hr}$. The rates 
page 22

in typical tap water are $1 \%$ of the respective seawater rates. The metal dissolves rapidly in hydrochloric acid but very slowly in nitric acid and lye solutions. Hydrogen reacts with the metal after an induction period which depends on the cleanliness of the metal and gas purity.

Plutonium often forms compounds in oxidation states from 3 to 6 although 2 and 7 are known. The properties of a few are:

$\begin{array}{lcccccc}\text { Compound } & \text { PuO2 } & \text { PuN } & \text { PuC } & \text { Pull2 } & \text { PuC13 } & \text { PuF3 } \\ \begin{array}{l}\text { melting point C } \\ \text { Heat of formation }\end{array} & 2240 & 2800 ? & 1654 & >1200 ? & 767 & 1396 \\ \mathrm{~kJ} / \mathrm{mol} & 1059 & 293 & 50 & 165 & 949 & 1553\end{array}$

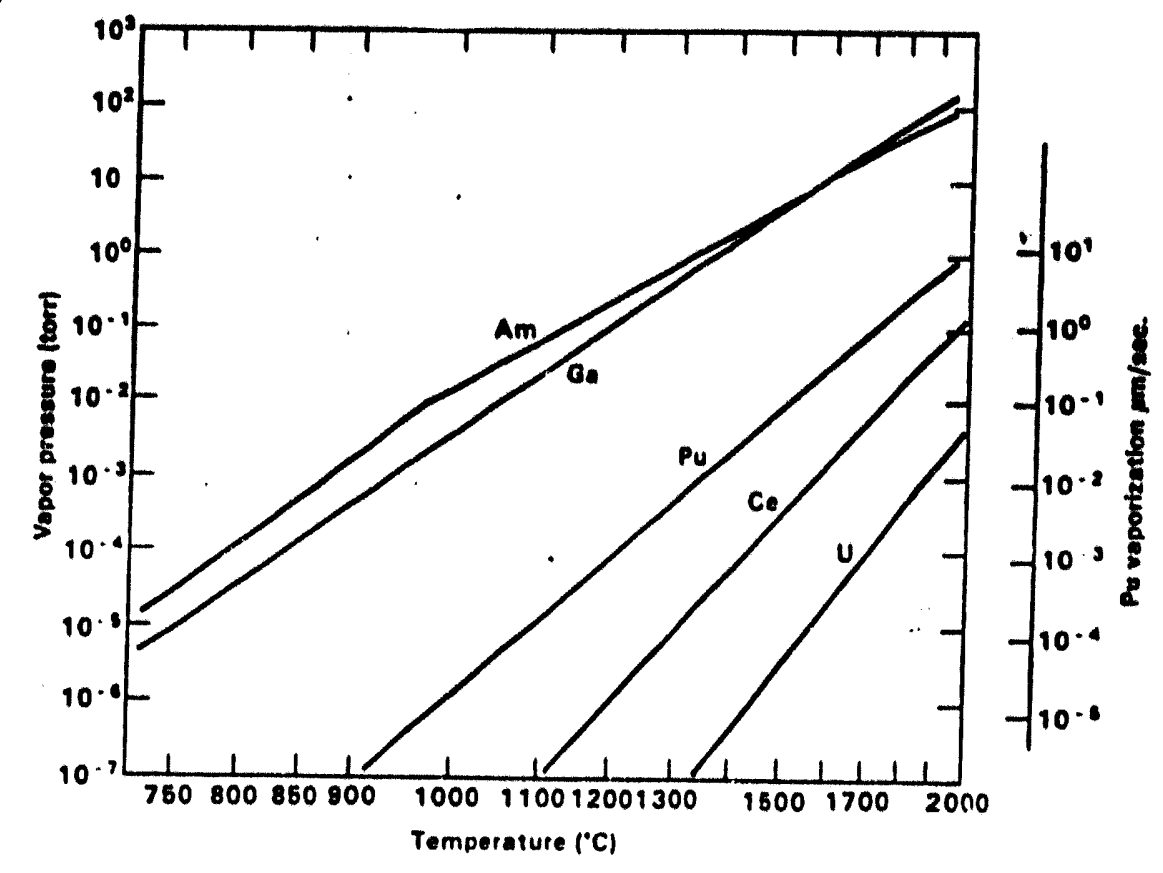

The vapor pressure of

$\mathrm{Pu}$ is shown in this

figure along with some other elements, some of which have been mentioned as possible stand-ins for Pu in experiments where using actual $\mathrm{Pu}$ is undesirable. The rate at which $\mathrm{Pu}$ metal evaporates is also shown on the right scale. To read this data you might pick some temperature, say $1200^{\circ} \mathrm{C}$, and from from the $\mathrm{Pu}$ line read that a $1 \times 10 \mathrm{E}-3 \mu \mathrm{m}$ thicl: ] vaporizr. rer second.

- Isotopes in Weapons Grade Plutonium:

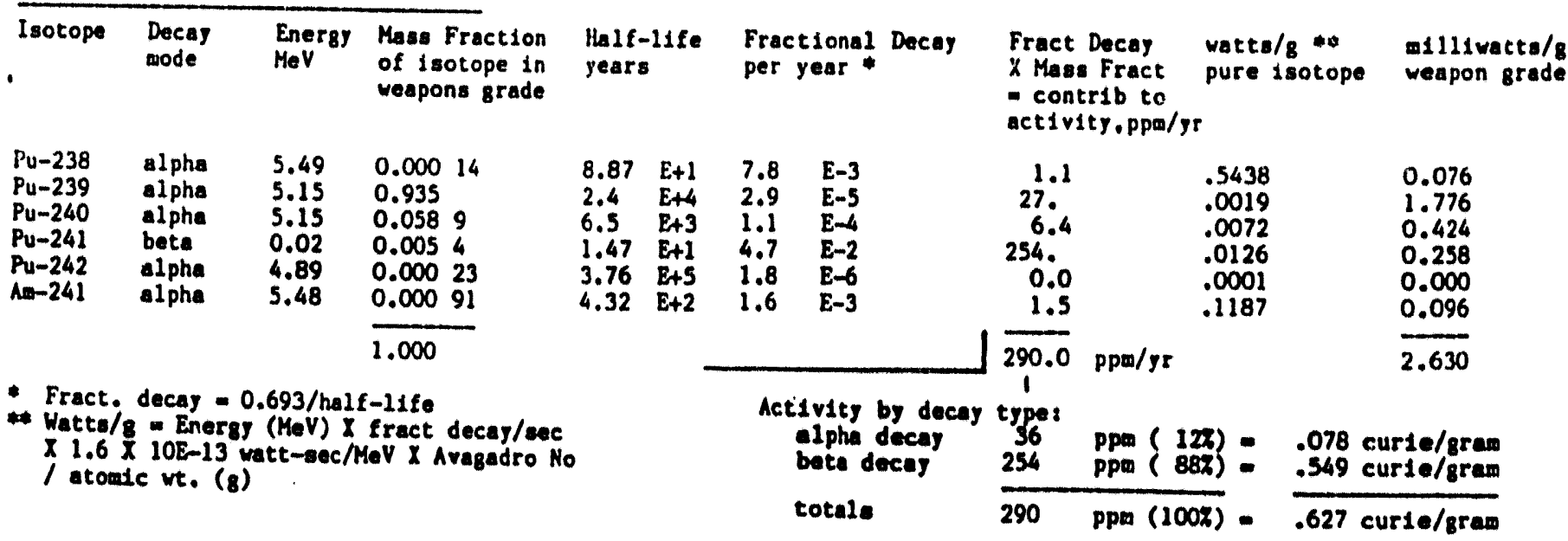




\section{GLOSSARY}

Terms mentioned in this report and in other toxicity and dispersal studies:

BNWL Battelle Northwest Laboratoriea, Richland, WA

C1 Curle, a unit of radioactive decay equaling $3.7 \times 10 E 10$ atomic disintegrations per second. $1 \mathrm{uCl}=3.7 \times 10 \mathrm{~L} 4 \mathrm{dps}$. $1 \mathrm{pC} 1=3.7 \times 10 \mathrm{E}-2 \mathrm{dps}$ or 2.22 disintegrations per minute.

EPA Environmental Protection Agency

IHE Insensitive high explosive, an explosive much less sensitive to hisating or Impact than conventional exposives.

ITRI Intulation Tox100108y Research Inst1tute, Albuquerque, NM

LANL Los Alamos National Laboratory, Los Alamos, NM

LCD Latent cancer deaths, a statistical estimate of the incresse above normal of cancer deathe Induced by some toxic exponure.

LLNL Lawrence LIvermore Natiunal Laboratory, Livermore, CA

Pu chemical symbol for the element, plutonium

RFP Rocky Flats Plant, Golden, CO

SNLA Sandia National Laboratory, Albuquerque, MM

$\boldsymbol{\mu} \mathrm{m}$

a micrometer, 40 microinches.

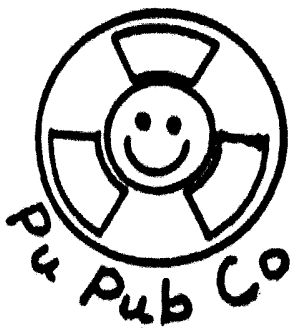



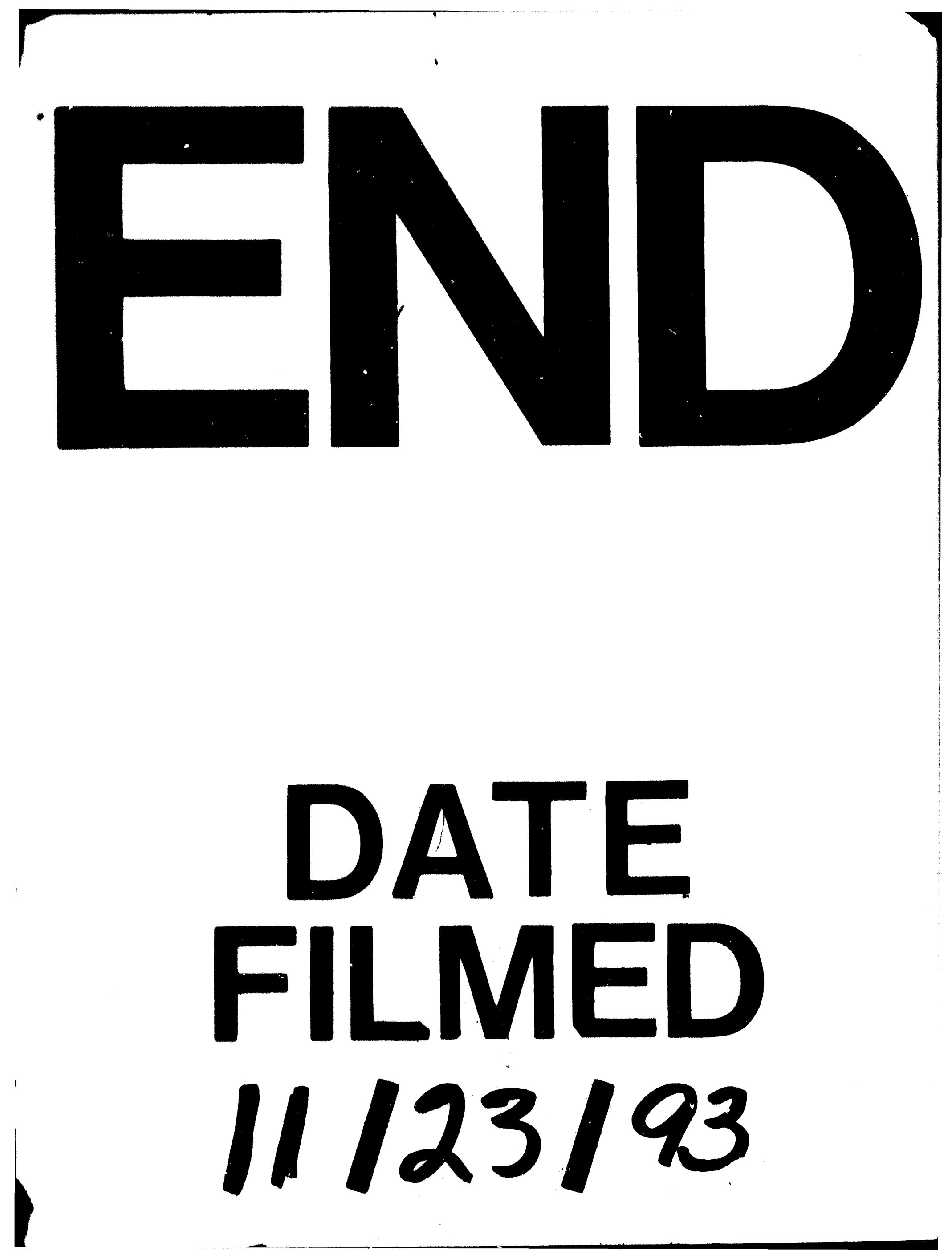
<smiles>C1CC1</smiles>

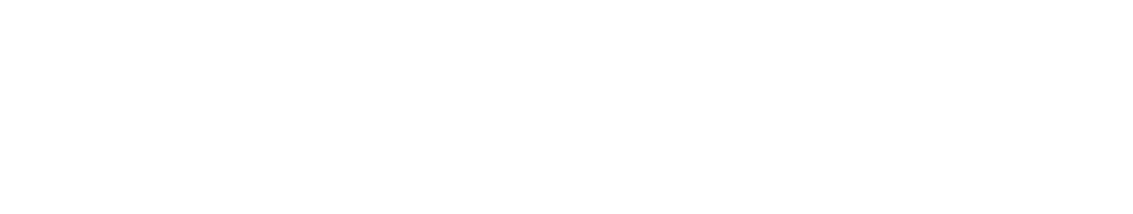

